\title{
Laboratory tests and modelling of mineral wool insulated steel sandwich panels
}

\author{
Anssi Laukkarinen ${ }^{1, *}$, Juha Vinha $^{1}$, Kristo Kalbe ${ }^{2}$, Jyrki Kesti ${ }^{3}$, Targo Kalamees ${ }^{4,2}$, and Erkki Honkakoski ${ }^{3}$ \\ ${ }^{1}$ Tampere University, Faculty of Built Environment, Building Physics, Tampere, Finland \\ ${ }^{2}$ Tallinn University of Technology, Department of Civil Engineering and Architecture, Tallinn, Estonia \\ ${ }^{3}$ Ruukki Construction Oy (SSAB), Hämeenlinna, Finland \\ ${ }^{4}$ Smart City Center of Excellence (Finest Twins), Tallinn University of Technology, Ehitajate tee 5, Tallinn, Estonia
}

\begin{abstract}
This study presents results from laboratory measurements of mineral wool insulated steel sandwich panels. The purpose of the work was to have a better understanding on the heat and moisture conditions inside sandwich panels and to study how the structure behaves in water leakage situation. The tests were done by sealing the structure from all sides and regulating the temperature on one side of the test structure while measuring the temperature and relative humidity conditions inside the structure. Water leakages were created by injecting liquid water onto the insulation layer. According to the results, water vapour pressure differences stayed relatively small both in stationary and dynamic conditions. This implies that the limiting factor for moisture source was the evaporation rate from the water leakage and that the vapour pressure throughout the insulation layer is determined strongly by the vapour pressure at the possible condensation layer. The paper discusses also the determination of sensor accuracy and impacts of a thermal bridge from the probe itself. Also, measurement results from a new radio wave monitoring method are presented.
\end{abstract}

\section{Introduction}

A steel sandwich panel is a prefabricated element structure, in which metal sheets are glued to rigid thermal insulation from both sides. The benefits of the structure are dimensional accuracy, fast installation and good air tightness, but at the same time it has a very low drying capacity. [1] The steel sandwich panels have been studied previously from the perspective of e.g. load-bearing capacity and fire behaviour [2,3], but moisture behaviour has received less attention in the current literature.

The purpose of this paper is to present results from laboratory tests of a test wall consisting of four sandwich panels. The paper analyses the uncertainty related to temperature and relative humidity sensors, compares results from two different probe installation methods and presents measurement results on the conditions that occurred during the tests. The paper presents also measurements results done with a new radio wave monitoring method.

\section{Methods and materials}

\subsection{Test walls}

The measurements were done using a climate chamber located at HAMK Tech in Finland (previously Hämeenlinna Sheet Metal Centre). The same sandwich panels were studied in a subsequent study in TalTech,
Estonia, which is presented in another paper at NSB2020 [4].

The climate chamber test included four sandwich panels of $1800 \mathrm{~mm} \times 1200 \mathrm{~mm} \times 230 \mathrm{~mm}$ each (w x h x $\mathrm{d}$, total area $8.64 \mathrm{~m}^{2}$ ), which were manufactured by Ruukki Construction Oy [5]. The sandwich panels were mounted to a movable timber frame and the total internal width and height of the test opening were $3200 \mathrm{~mm}$ x 1900 $\mathrm{mm}$ when viewed from the climate chamber side. Fig. 1 shows the test wall from the interior (warm) side.

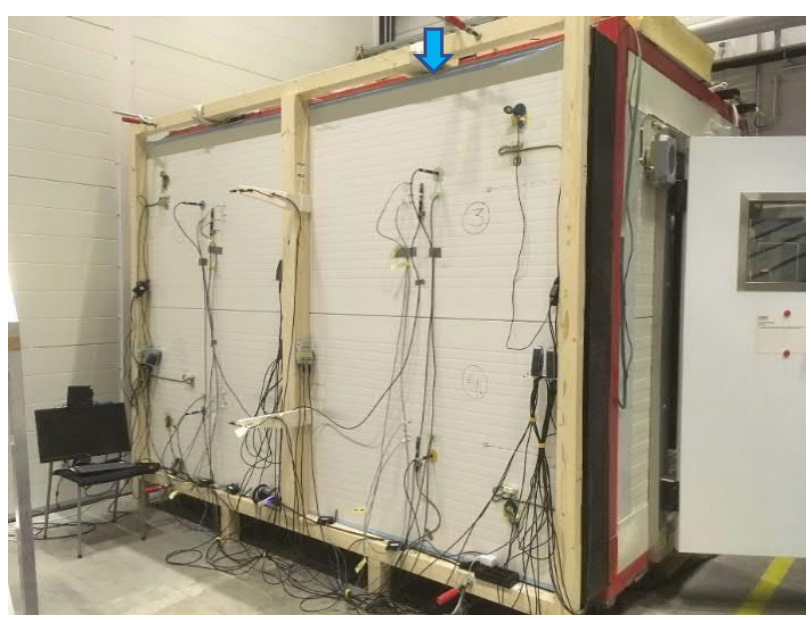

Fig. 1. Wall tests at HAMK Tech. Blue arrow points the location, where additional water was injected during the tests. Radio transceivers were installed close to the exterior corners of each element.

\footnotetext{
* Corresponding author: anssi.laukkarinen@,tuni.fi
} 
The outer panel edges were sealed with taped PE-foils and steel sheet U-profiles covering them. Small water escapes were arranged to the middle-bottom part of the wall, which are also part of the sandwich panel system. Fig. 2 shows the panel structure and the vertical joint at the middle of the test wall.

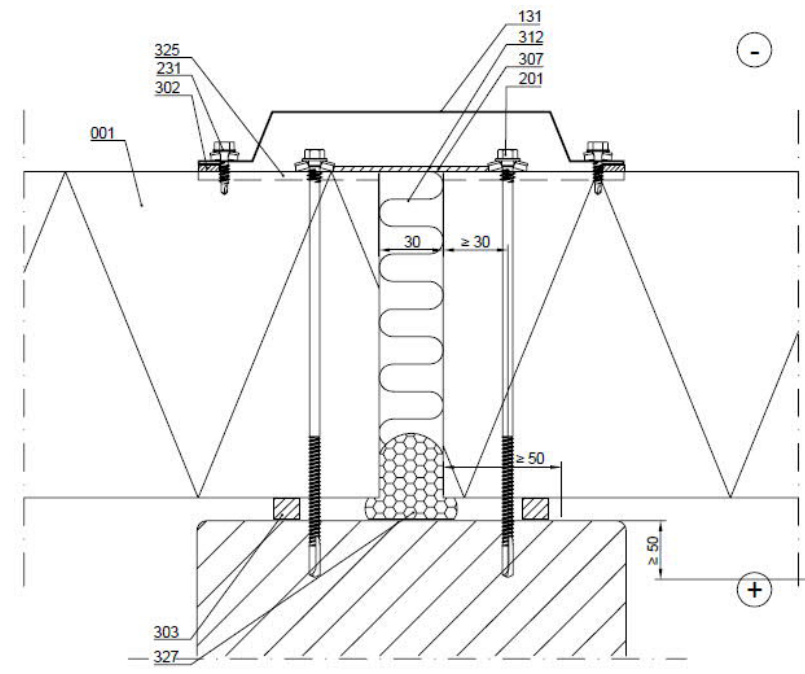

001. Sandwich panel SPA Energy

131. /EA1JV1/ Vertical joint flashing

201. Self-drilling screw, washer with sealing 231. Flashing fastener, washer with sealing 302. /EA3SS410/ Sealing strip

/EA3SS510/ Sealing band EPDM for

flashing

303./EA3SS1210/ Sealing strip

07. /EA3JSN7525/ Joint sealing Nordic

312. /EAWS5657850/ Mineral wool band

325. /EA3SM310_/ Elastic sealant during inst. to outer female groove in length equivalent to vertical joint flashing width

327. Elastic polyurethane foam

Fig. 2. Vertical joint in the middle of the panel wall, adapted from [5]. The indoor side $(+)$ is towards to photographer in Fig. 1.

The panels use Paroc high density stone wool as insulation material $\left(\rho=85 \mathrm{~kg} / \mathrm{m}^{3}, \lambda_{D}=0.040 \mathrm{~W} /(\mathrm{m} \cdot \mathrm{K})\right)$. According to the mineral wool manufacturer specification [6], at adsorption the hygroscopic moisture content of the stone wool is approximately $\sim 0 \mathrm{~kg} / \mathrm{m}^{3}$ at $50 \% \mathrm{RH}$ and 0.1 $\mathrm{kg} / \mathrm{m}^{3}$ at $83 \% \mathrm{RH}$. At desorption, the moisture content values are reported to be $0.09 \mathrm{~kg} / \mathrm{m}^{3}$ at $50 \% \mathrm{RH}$ and 0.22 $\mathrm{kg} / \mathrm{m}^{3}$ at $83 \% \mathrm{RH}$. The $98 \% \mathrm{RH}$ moisture content is set at $0.30 \mathrm{~kg} / \mathrm{m}^{3}$. In general, the hygroscopic moisture content of stone wool is in the order of $\leq 1 \mathrm{~kg} / \mathrm{m}^{3}$.

The conditions on the indoor air (the side seen in Fig. 1) were fairly constant throughout the measurement period, being $18.8 \pm 0.7{ }^{\circ} \mathrm{C}, 25 \pm 5 \% \mathrm{RH}$ and $540 \pm 100$ $\mathrm{Pa}\left(p_{v}\right)$. The air temperature inside the climate chamber was adjusted to varying cold temperatures to study the thermal and moisture response of the sandwich panels to these step-wise changes (see Ch. 3).

\subsection{Temperature and relative humidity measurement device accuracy}

Temperature and relative humidity measurement devices have a finite accuracy which has to be taken into account when designing measurement and interpreting the results. The GUM [7] presents a method to calculate and report a value representing the uncertainty related to measurement results. It is also used as a reference for this section, if not otherwise stated. The GUM recommends reporting the combined standard uncertainty (standard deviation), which is calculated by combining the variances from individual error sources according to Eq. (1).

$$
u_{c}(y)=\sqrt{\sum_{i=1}^{N}\left(\frac{\partial f}{\partial x_{i}}\right)^{2} u^{2}\left(x_{i}\right)}
$$

where $u_{c}(y)$ is the combined standard uncertainty for the output quantity $y, f$ is the functional relationship between input quantities $x_{i}$ and the output quantity $y$ and $u\left(x_{i}\right)$ are the standard uncertainties of input quantities $x_{i}$. Eq. (1) assumes that in the vicinity of $\boldsymbol{x}$, a first-order Taylor series approximation describes sufficiently the function $f$ and that the standard uncertainties $u\left(x_{i}\right)$ are not correlated.

The function that is studied here is the definition of relative humidity, written as: $f=p_{v}(\varphi, T)=\varphi$. $p_{v, \text { sat }}(T)$, where $p_{v}$ is the vapour pressure $(\mathrm{Pa}), \varphi$ is the relative humidity (-), $\quad p_{v, s a t}$ is the saturation vapour pressure $(\mathrm{Pa})$ and $T\left[{ }^{\circ} \mathrm{C}\right]$ is the temperature. The saturation vapour pressure is calculated with the Magnus formula (over liquid water also in $<0{ }^{\circ} \mathrm{C}$ temperatures) [8]:

$$
p_{v, \text { sat }}(T)=611.2 \cdot \exp \left(\frac{17.62 T}{243.12+T}\right)
$$

The partial derivatives for equation (1) can be solved analytically and are:

$$
\begin{aligned}
& \frac{d}{d T}\left(p_{v}(\varphi, T)\right)=p_{v} \cdot \frac{17.62 \cdot 243.12}{(243.12+T)^{2}} \\
& \frac{d}{d \varphi}\left(p_{v}(\varphi, T)\right)=p_{v, s a t}(T)
\end{aligned}
$$

The standard uncertainties were determined from manufacturer data sheets and internal calibration guidelines. The accuracy data was in the form: $\pm a$, where $a$ describes the half-width of the rectangular probability density distribution containing the true value of the measurand $(T$ or $\varphi)$. For a rectangular probability density distribution, the variance is: $u^{2}\left(x_{i}\right)=a^{2} / 3$.

After the combined standard uncertainty $u_{c}$ is calculated, the expanded uncertainty $U=k u_{c}(y)$ can be determined. Correlating the coverage factor $k$ to exact confidence levels is difficult, so rule-of-thumb values are typically used. In this study, the coverage factors of $k=1$, 2 and 3 were used.

The measurement setup included Rotronic data loggers and HC2-S capacitive humidity sensors. Data for these is given in Table 1 and their behaviour is analysed further in Ch. 3.1.

Table 1. HygroLog HL-NT3 data logger with HygroClip2 $\mathrm{HC} 2-\mathrm{S}$ probes. Accuracy values consider temperature range $-30 \ldots 30^{\circ} \mathrm{C}$.

\begin{tabular}{|l|l|l|}
\hline & Humidity & Temperature \\
\hline Accuracy [9] & $\pm 2.3 \ldots \pm 0.8 \% \mathrm{RH}$ & $\pm 0.3 \ldots \pm 0 .{ }^{\circ} \mathrm{C}$ \\
\hline $\begin{array}{l}\text { Repeatability } \\
{[10]}\end{array}$ & $0.3 \% \mathrm{RH}$ & $0.05{ }^{\circ} \mathrm{C}$ \\
\hline Drift [10] & $<1 \% \mathrm{RH} /$ year & $<0.1^{\circ} \mathrm{C} /$ year \\
\hline Calibration $(*)$ & $\pm 2.0 \% \mathrm{RH}$, at $20^{\circ} \mathrm{C}$ & $\pm 0.5^{\circ} \mathrm{C}$, at $20^{\circ} \mathrm{C}$ \\
\hline
\end{tabular}

(*) Value used at calibration, internal guideline. 
The Rotronic sensors were tested against calibrated T and RH sensor using saturated salt solutions at Tampere University of Technology building physics research group before the laboratory tests. The sensors were accepted for measurements if they passed the calibration limits in Table 1. The total measurement time was 12 weeks, so the maximum drift is assumed to be (12 weeks / 52 weeks/year) $* 1 \% \mathrm{RH} /$ year $=0.23 \% \mathrm{RH}$ and similarly for temperature measurement.

The influence of different error sources was evaluated also numerically using the Monte Carlo method. The numpy.random. uniform function was used to generate random errors for each error source in Table $1(\mathrm{~N}=5000)$.

From the Monte Carlo simulations the 68, 95 and 99 $\%$ empirical cumulative distribution function (ecdf) values were calculated, which correspond to $0.99,1.96$ and 2.58 standard deviations away from the mean at normal distribution. The calculations were repeated for percentage values corresponding to 1,2 and 3 standard deviations away from mean, but likely due to the rectangular density functions of the input data, the influence to results was small (based on visual inspection of the result figures).

The combined/expanded uncertainty according to GUM and the ecdf values based on Monte Carlo simulations were calculated for a temperature range of $-20 \ldots 20^{\circ} \mathrm{C}$, because $\mathrm{T}$ and $\mathrm{RH}$ accuracies depend on temperature [9]. Temperature-dependent relative humidity was used for calculations, with $90 \% \mathrm{RH}$ in -20 ${ }^{\circ} \mathrm{C}$ and $40 \% \mathrm{RH}$ in $+20{ }^{\circ} \mathrm{C}$.

For the difference of two means (a linear combination of input values), the combined uncertainty was derived from Eq. (1) and is:

$$
u_{c, \bar{x} 1-\bar{x} 2}=\sqrt{u_{1}^{2} / N_{1}+u_{2}^{2} / N_{2}}
$$

where $u_{1}$ and $u_{2}$ are the standard uncertainties for one sensor in groups 1 and 2 respectively (same for each sensor per group), and $N_{1}$ and $N_{2}$ are the sample sizes for each mean. The Rotronic probes were tested after the measurements against a calibrated reference sensor and the relative humidity corrections at $94 \% \mathrm{RH}$ and $20{ }^{\circ} \mathrm{C}$ were used for calculating a few statistics on how the relative humidity measurements had maintained their accuracy during the sandwich panel tests.

In addition, Humia B3 sensors were used in the measurements. Results from those sensors were used in the comparison studies described in Ch. 2.3 and 3.2. According to the manufacturer data sheet [11], the Humia B3 accuracy is $\pm 0.3{ }^{\circ} \mathrm{C}$ at recommended temperature range $0-50{ }^{\circ} \mathrm{C}$ and \pm 0.6 at temperature range $-30-60{ }^{\circ} \mathrm{C}$. The relative humidity accuracy is $\pm 3 \% \mathrm{RH}$ at recommended relative humidity range $20-80 \% \mathrm{RH}$ and \pm 5 $\%$ RH at $0-100 \%$ RH. All the presented results were measured with Rotronic probes, except for the two measurement points in the depths of $100 \mathrm{~mm}$ and $180 \mathrm{~mm}$ from the interior surface in Fig. 7.

\subsection{Effects from probe installation}

Besides the uncertainty related to measurement results from an ideally installed sensor, the measurement equipment itself can affect the conditions that are measured. Generally, the measurement device should be placed in such a way, that the equipment influences the conditions in the measurement position as little as possible, but this might not always happen or be possible.

This part of the paper compares measurement results from two types of probe installation methods. The two panels on the right-hand side of Fig. 1 were equipped with HC2-S probes installed both perpendicularly to panels (through the interior metal sheet) and parallel to the panels (through the PE-foil at the vertical right-hand side). There were measurement points both at the interior and exterior surface of the thermal insulation ( 8 probes in total for the comparison).

The HC2-S probe diameter is $15 \mathrm{~mm}$ and the length of the filter cap $35 \mathrm{~mm}$ (whole probe length $180 \mathrm{~mm}+$ cable). The sensor is in the centre of the filter cap, so the measurement point was inside the mineral wool either 35 $\mathrm{mm} / 2 \approx 18 \mathrm{~mm}$ (perpendicular) or $15 \mathrm{~mm} / 2 \approx 8 \mathrm{~mm}$ (parallel) from the metal sheet next to the probe.

The impact of the measurement probe on the measured conditions was analysed also by using simulation programs Delphin [12] and THERM [13]. The calculations were done using 2D models, which means that the probe is modelled as a slab instead of a cylinder. This creates a stronger thermal bridge from the probe in simulations, compared to otherwise similar 3D situation. The measurement data in Fig. 7 and 8 is from the Humia B3 sensors installed perpendicularly to depths of $100 \mathrm{~mm}$ and $180 \mathrm{~mm}$ from the interior surface.

\subsection{Conditions inside the sandwich panels}

The third and last section of the paper presents temperature, relative humidity and vapour pressure results from the tests. The analysed results are from the probes installed perpendicularly, because of their larger number in the tests (compared to parallel installation) and the benefit of using similar installation method compared to mixing results from different installation methods. Perpendicularly installed Rotronic probes were placed to monitor the interior and exterior surface of the mineral wool insulation at the middle of each element (eight points in total).

The impact of water leakages was studied by injecting water onto the insulation layer (upper edge of top-right panel) with a large syringe attached to a plastic pipe, which again was tightened to go through the PE-foil. The total volume of the stone wool insulation material was $8.64 \mathrm{~m}^{2} \cdot 0.23 \mathrm{~m}=1.99 \mathrm{~m}^{3}$, so according to the sorption curves, the moisture content at $98 \% \mathrm{RH}$ would be 0.3 $\mathrm{kg} / \mathrm{m}^{3} \cdot 1.99 \mathrm{~m}^{3} \approx 0.6 \mathrm{~kg}$. Because of the small hygroscopic moisture capacity of the mineral wool, water was injected in multiple stages. There was unit conversion misunderstanding during the tests, so more water was added than originally intended. The injection was done first five times in volumes of $864 \mathrm{~g}\left(100 \mathrm{~g} / \mathrm{m}^{2}\right)$ to the centre-top of the top-right panel at $4^{\text {th }}, 5^{\text {th }}, 11^{\text {th }}$ and twice $14^{\text {th }}$ of December 2018 (blue arrow in Fig. 1). The total amount of added water with the first five smaller injections was $5 \cdot 0.864 \mathrm{~g} / 1.99 \mathrm{~m}^{3}=2.17 \mathrm{~kg} / \mathrm{m}^{3}$. 
After these, water was added once more for a total of $1000 \mathrm{~g}$ on $11^{\text {th }}$ January 2019 . Of the last injection of water, $510 \mathrm{~g}$ leaked out through the bottom of the test wall in about 15 minutes after injection (water was collected from the bottom and weighed). No water leakages occurred from the earlier injections. The exact distribution of liquid water inside the panels is not known.

In the following section, " 0 " means a probe installed to measure the conditions in the thermal insulation next to the interior metal sheet and " 230 " means a similar probe installed next to the exterior metal sheet at the climate chamber side.

\subsection{Radio monitoring}

Radio waves are a form of electromagnetic radiation with a longer wavelength than visible light or infrared radiation. They can penetrate through building materials, but their behaviour also includes phenomenon such as reflection and attenuation $[14,15]$. A new [16] radio wave monitoring system has been developed, which was also included in the sandwich panel laboratory tests. The electronic devices can be outside the sandwich panel and they can also be completely encapsulated from air, moisture and possible contaminants. The physical radio equipment is compatible with the IEEE standard 802.15.4a, which will include improved security features in the future after the standard update finishes [17].

In this test setup, four transceivers capable of very short pulse duration and wide spectrum were installed on the wall panels (one in each). Each of the transceivers communicated with other ones and the channel impulse response (CIR) data was recorded. The output from one transceiver was a time series of dimensionless numbers between 0 and 1 with a known code that was opened and analysed at the receiver side. The goal of this section was to study, how the radio channel impulse response estimation result change as the conditions inside the panel and the panel configuration change.

\section{Results and discussion}

\subsection{Measurement device accuracy}

The combined and expanded uncertainty and the Monte Carlo simulation results for temperature measurement accuracy are presented in Fig. 3. For temperature uncertainty, the combined standard uncertainty $u_{c, T}$ corresponded well to the one-sigma (68\%) values from Monte Carlo simulations, both being close to $\pm 0.3{ }^{\circ} \mathrm{C}$ $(k=1)$ throughout the temperature range $-20 \ldots 20^{\circ} \mathrm{C}$. The expanded uncertainty $U(k=2)$ was similar to the $99 \%$ Monte Carlo results, being approximately $\pm 0.6{ }^{\circ} \mathrm{C}$. The expanded uncertainty with $k=3$ was the largest, being approximately $\pm 0.9^{\circ} \mathrm{C}$. Because the expanded uncertainty is limited only by the selection of coverage factor $k$, the hand calculation formulas were able to produce larger uncertainty bounds than the Monte Carlo simulation.

Fig. 4 shows the expanded uncertainty $(k=1,2$ and 3$)$ and the results from Monte Carlo simulations for relative humidity. Compared to temperature uncertainty, relative humidity shows a clear step-wise behaviour, which is a result of the temperature-dependent input values.

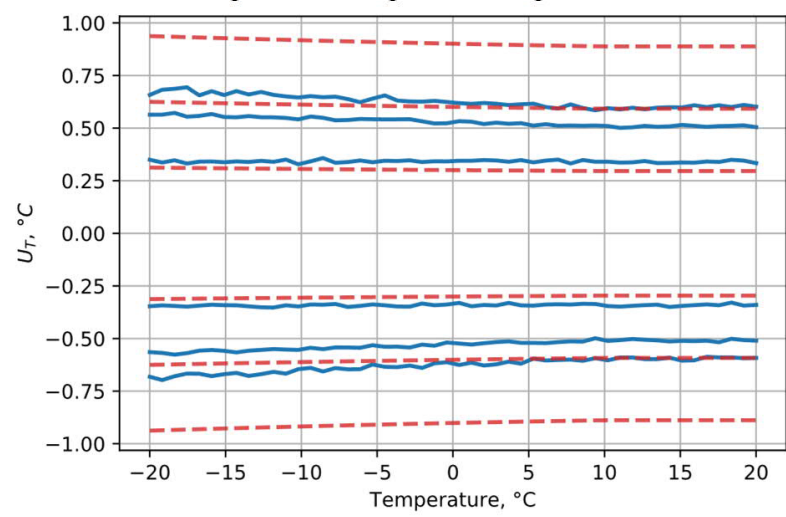

Fig. 3. Combined and expanded temperature measurement uncertainty according to $\operatorname{GUM}(k=1,2$ and 3, dashed lines) and the 68, 95 and $99 \%$ confidence intervals from Monte Carlo simulations (solid lines).

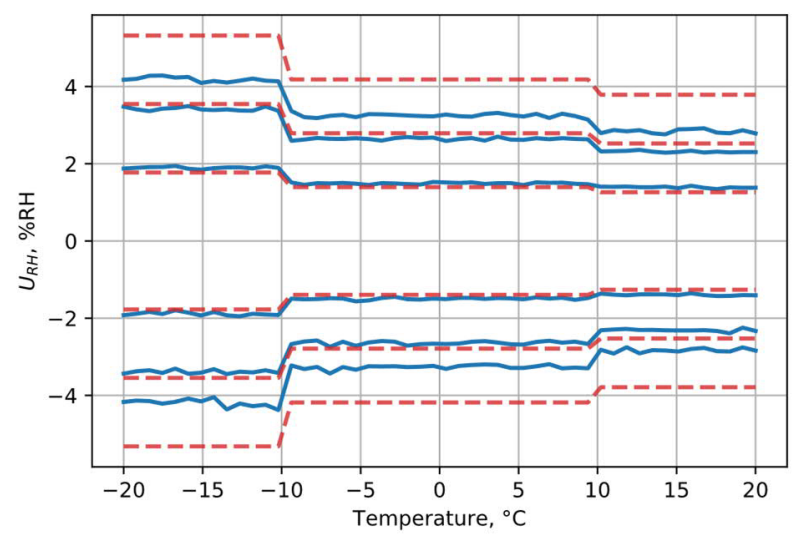

Fig. 4. Combined and expanded relative humidity measurement uncertainty ( $k=1,2$ and 3 , dashed lines) according to GUM and the 68,95 and $99 \%$ confidence intervals from Monte Carlo simulations (solid lines).

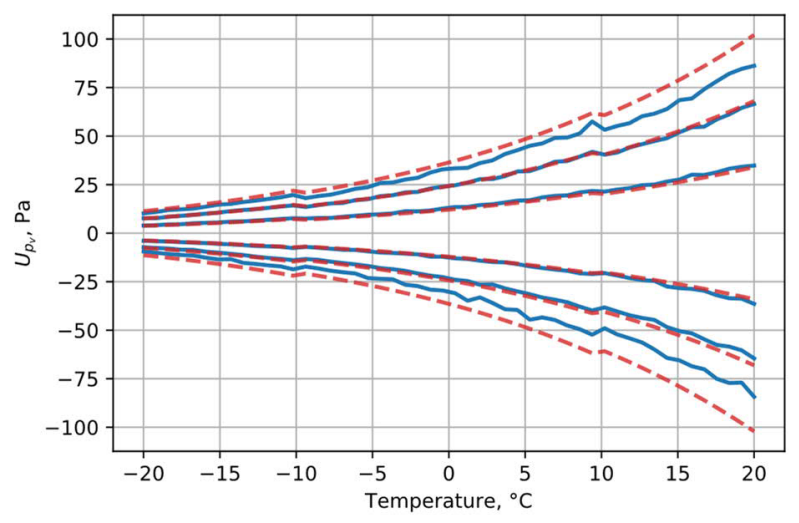

Fig. 5. The combined and expanded vapour pressure uncertainty according to GUM ( $k=1,2$ and 3, dashed lines) and the 68,95 and $99 \%$ confidence intervals from Monte Carlo simulations (solid lines).

According to Fig. 4, the correlation between combined and expanded uncertainty and Monte Carlo simulations is similar to temperature measurement uncertainty. The combined standard uncertainty $u_{c, R H}(k=1)$ and the expanded uncertainty $U(k=2)$ corresponded quite well to 
68 and $95 \%$ cdf values from Monte Carlo simulations, whereas the case $k=3$ produced limits bigger than the Monte Carlo simulations. The expanded uncertainty with $(k=2)$ was approximately $\pm 4 \% \mathrm{RH}$ in temperature range $<-10{ }^{\circ} \mathrm{C}$ and $\pm 2.5 \% \mathrm{RH}$ in temperature range $>+10{ }^{\circ} \mathrm{C}$.

According to Fig. 5, there is a nonlinear correlation between temperature and vapour pressure measurement uncertainty, which is due to piecewise constant relative humidity measurement accuracy, but exponentially increasing saturation vapour pressure. The results from the two calculation methods were close to each other. For $k=1 / 68 \%$ and $k=2 / 95 \%$, but also for $k=3 / 99 \%$ results were relatively close to each other, especially in colder temperatures. The combined standard uncertainty was in the order of $\pm 10 \mathrm{~Pa}$ at $-5{ }^{\circ} \mathrm{C}$ and $\pm 35 \mathrm{~Pa}$ at $+20{ }^{\circ} \mathrm{C}$.

For the $\mathrm{n}=22$ relative humidity accuracy postevaluations $\left(R H_{\text {reference }}-R H_{\text {probe }}\right)$ at $94 \% \mathrm{RH}$ the descriptive statistics were: 0.44 ( $\mathrm{min}), 1.58$ (mean), 1.43 (median), 1.05 (std) and $5.21(\max ) \% \mathrm{RH}$. This means that the probes had maintained their RH measurement accuracy within the limits of Table 1, but all the sensors gave lower $\mathrm{RH}$ values at the end of the test period compared to the reference sensor.

\subsection{Effects from probe installation}

The impact of the probe installation type is studied in Fig. 6 , which shows the difference of mean temperatures measured with the two installation methods.

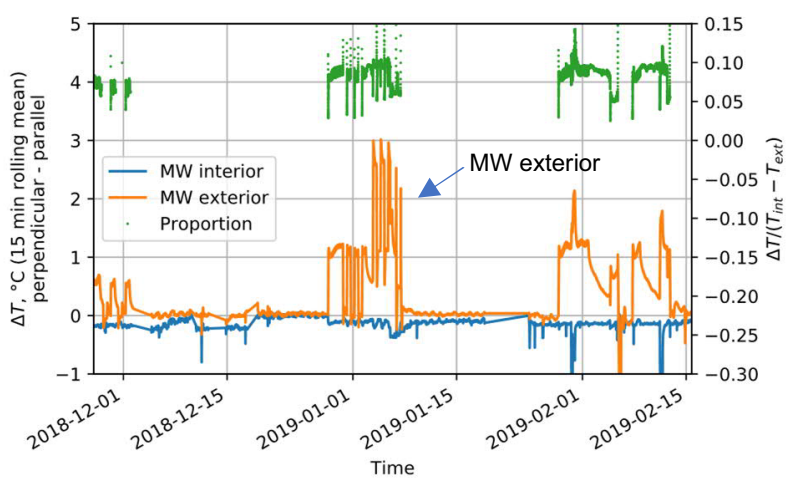

Fig. 6. Temperature difference between two types of probe installation methods, for interior and exterior surface of the thermal insulation (left axis). The exterior side shows clear impact from the installation method, when there was temperature difference over the test wall. Right axis shows the same temperature difference at the exterior side divided by the total temperature difference from the warm to cold side (prop.).

According to Fig. 6, the installation method had a clear impact on the results when there was a temperature difference between the warm indoor air and the measurement point. The combined standard uncertainty for the difference of two means is calculated to be: $\sqrt{0.3^{2} / 2+0.3^{2} / 2}=0.3{ }^{\circ} \mathrm{C}$, which is exceeded at the exterior surface when there is temperature difference over the test wall. In that case, the temperature difference between the two installation methods was $1 \ldots 3{ }^{\circ} \mathrm{C}$ (Fig. 6) when the temperature difference over the test wall was $10 \ldots 20^{\circ} \mathrm{C}$. By removing the time steps when the temperature difference between the two installation methods was less than $0.3{ }^{\circ} \mathrm{C}$ and by dividing the difference between the methods with the temperature difference over the insulation layer, the temperature increase from the probe installation method was about 11 $\%(10-15 \%)$ of the temperature difference over the insulation layer.

Also, the average vapour pressure was different between the two installation methods. The increase in vapour pressure at $+20^{\circ} \mathrm{C}$ temperature was in the order of $50 \ldots 200 \mathrm{~Pa}$, while the standard uncertainty for the difference of two means is approximately $\sqrt{30^{2} / 2+30^{2} / 2}=30 \mathrm{~Pa}$. This suggests that also the vapour pressure conditions were affected by the probe installation method at both the interior and exterior surface of the thermal insulation. However, the difference was small and/or masked to other factors when conditions varied dynamically.

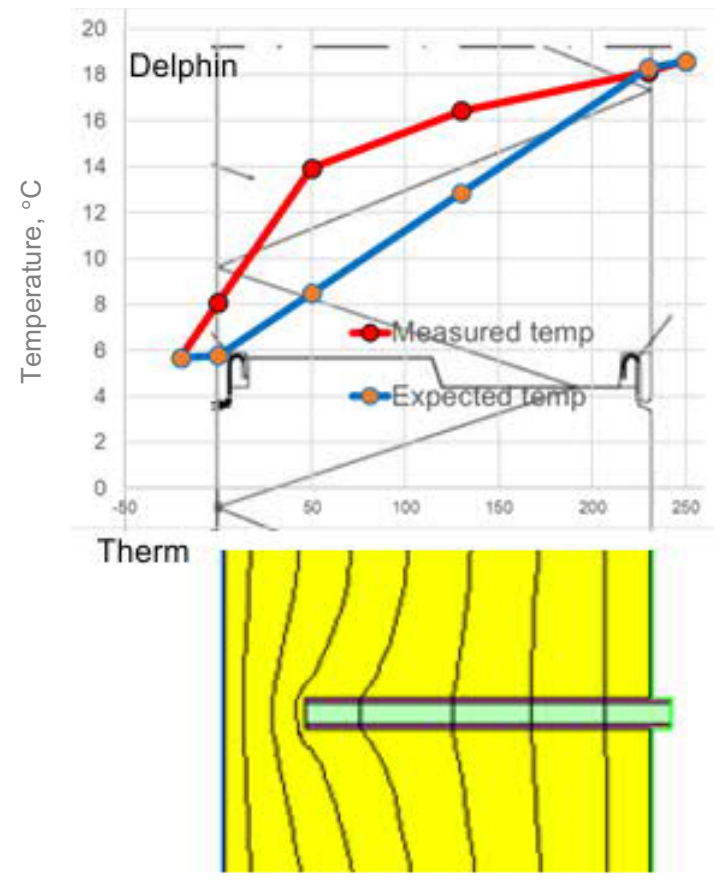

Fig. 7. The comparison of measured and expected (by Delphin) temperatures and the influence of perpendicular probe on temperature field (modelled by THERM).

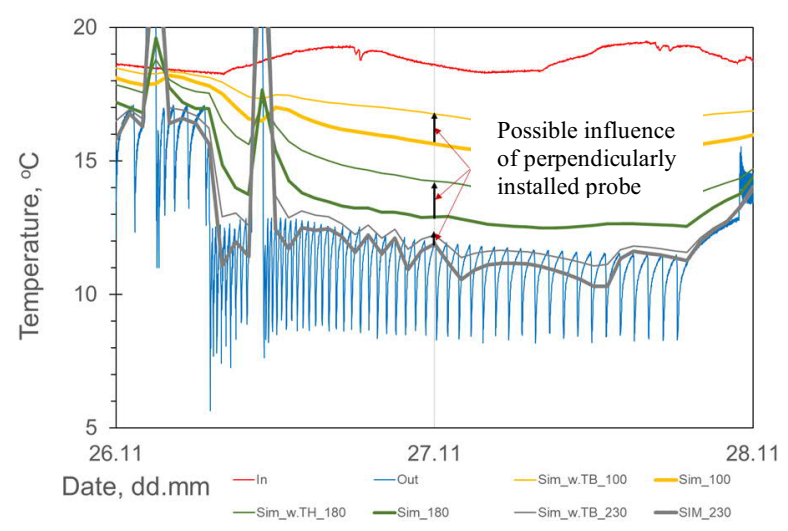

Fig. 8. Temperatures from Delphin simulations with and without a "probe".

Based on the simulation results in Fig. 7 and 8, the temperature increase from the thermal bridge was about 0.5-1.5 ${ }^{\circ} \mathrm{C}$ when the temperature difference over the 
structure was a little bit less than $10^{\circ} \mathrm{C}$. This is in the same order of magnitude, compared to what was calculated from the measurements.

\subsection{Conditions inside the sandwich panels}

Fig. 9 and 10 show the average temperature and relative humidity at the interior and exterior surface of the thermal insulation layer during laboratory tests. The goal of the first few days was to use small $\left(\Delta T=5{ }^{\circ} \mathrm{C}\right)$ temperature differences to create a reference data set with as simple building physical behaviour as possible. However, from the viewpoint of Figs. 9 and 10, the temperature drops at the cold side could have been larger (e.g. $\Delta T=10^{\circ} \mathrm{C}$ ) and the stationary conditions could have lasted longer, for example 2-4 days, instead of the current one day.

The vertical blue dashed lines in Figs. 9 and 10 show the first five moments when water was added onto the insulation layer. The temperatures did not change much, but relative humidity started to steadily increase in all the measurement points around the insulation layer (besides the averages in Fig. 10). Relative humidity and vapour pressure behaved very similarly because the temperature was constantly close to $+20^{\circ} \mathrm{C}$.

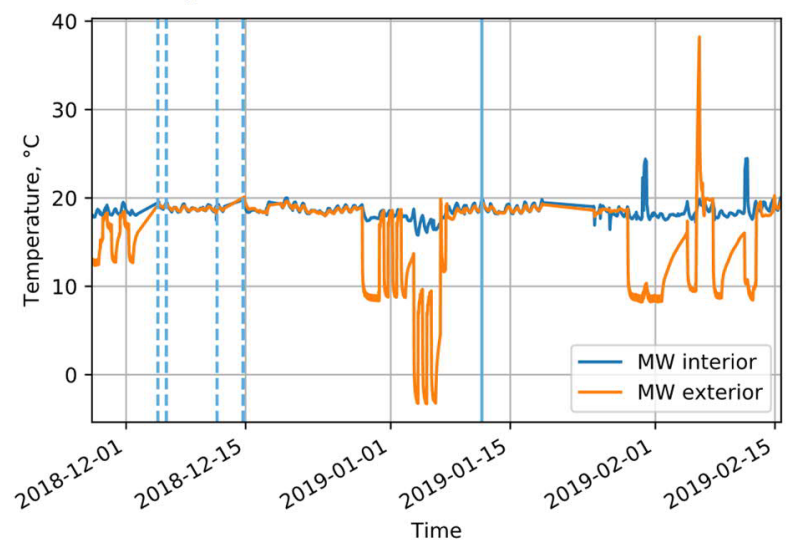

Fig. 9. Average temperature at interior and exterior (lower line) surface of the thermal insulation. The step-wise changes at the beginning of the measurement period could have been longer.

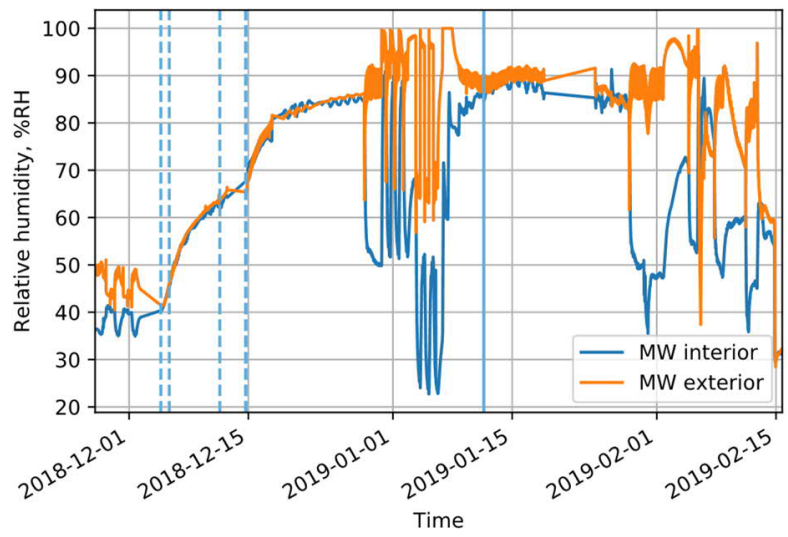

Fig. 10. Average relative humidity on the interior and exterior (upper line) surface of the thermal insulation.

The average relative humidity rose from $40 \% \mathrm{RH}$ to $80 \% \mathrm{RH}$ in two weeks and continued to have a slow increase after that. If we compare the amount of added water $(4.32 \mathrm{~kg})$ to the sorption curve values from Ch. 2.1 $\left((0.1-0) \mathrm{kg} / \mathrm{m}^{3} \cdot 8.64 \mathrm{~m}^{2} \cdot 0.23 \mathrm{~m}=0.2 \mathrm{~kg}\right)$, relative humidity increased much less than what the change in sorption curve values would be. Because no leakages were noticed during the initial part of the tests, there must have been either additional moisture evaporation from the structure during the test or steady-state conditions have not been reached, of which the latter is considered to be the probable explanation.

Based on the steady increase of moisture content in all measurement points, it seems that the limiting factor for relative humidity increase in the insulation layer was the evaporation speed of the injected water, instead of e.g. the diffusion speed inside the insulation layer. This would mean that the moisture leakage (e.g. $1 \%$ from winddriven rain) inside an open porous, non-capillary mineral wool insulation should be modelled as a maximum water content with varying volume, instead of the currently more common approach of varying moisture content increase to a constant volume.

Relative humidity values experienced an increase after the last water injection in January 2019, but the impact was not as big as with the previous water injections. This is assumed to be because the relative humidity in the pore air was already high, so the evaporation was slow.

A more detailed view of the dynamic temperature conditions is given in Figs. 11-14, in which " $0 . .$. " and "230.." mean the interior and exterior surface of the mineral wool insulation. The measurement points "...1", “...2", ... mean the panels nr. 1, 2, .. at the top-left, bottom-left, top-right and bottom-right positions in Fig. 1. "MW" stands for mineral wool. Fig. 11 and 12 show the temperature at the exterior surface and the vapour pressure at the interior surface of the insulation layer respectively.

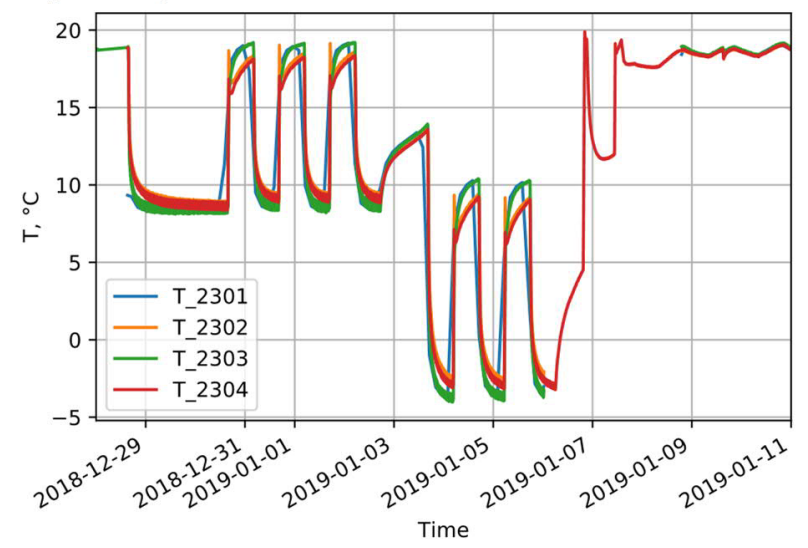

Fig. 11. Temperature at the exterior surface of MW.

Based on Figs. 11 and 12, when the temperature in the climate chamber decreased, the water vapour pressure in the interior side of the thermal insulation decreased. The decrease of vapour pressure was visible also as lower relative humidity values because the temperature stayed relatively constant at the interior surface of the insulation layer. Because vapour pressure at the interior surface changed, there must have been a moisture transfer process, which has affected the amount of water vapour in the pore air. 
Based on Figs. 12 and 13, the vapour pressures behaved similarly both at the interior and exterior surfaces of the insulation layer and between probes of perpendicular and parallel installation. This means that although vapour pressure varied in time, it was fairly constant throughout the insulation layer at each time.

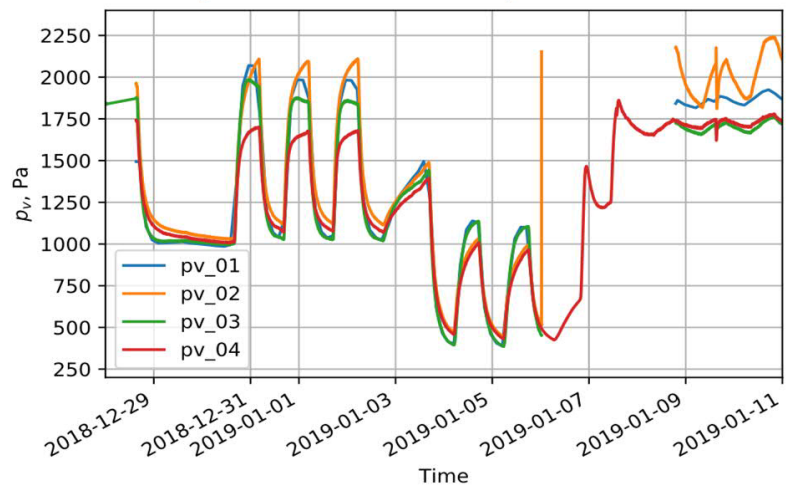

Fig. 12. Vapour pressure at the interior surface of MW.

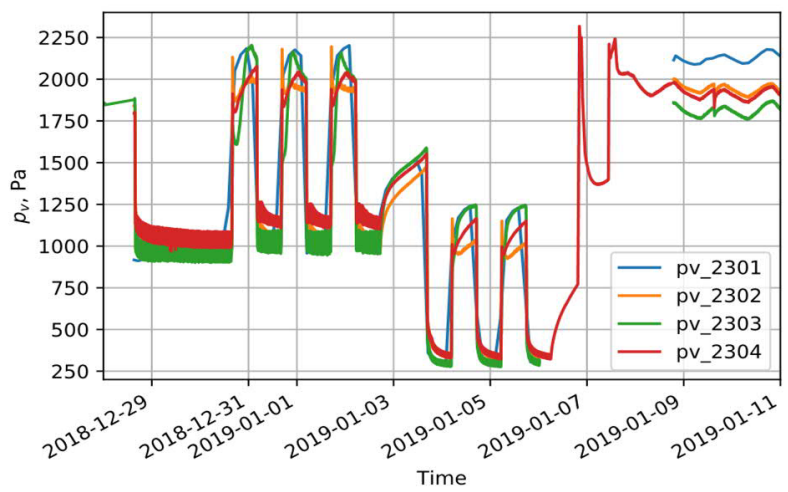

Fig. 13. Vapour pressure at the exterior surface MW.

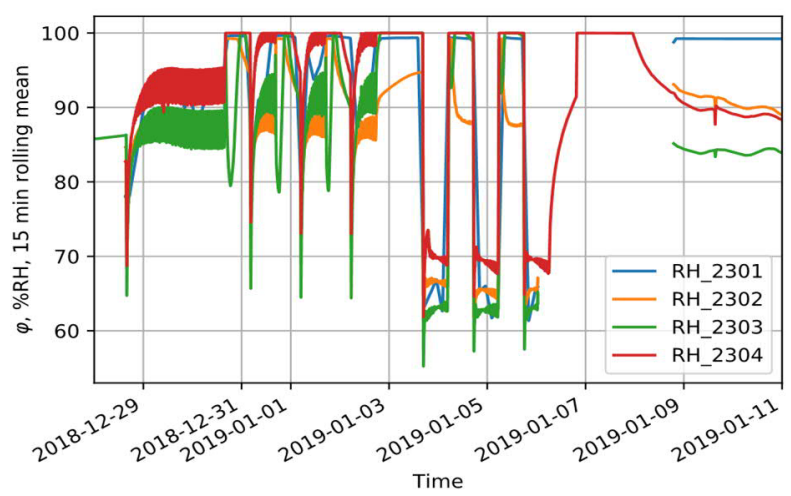

Fig. 14. Relative humidity at the exterior surface of MW.

In the period surrounding 2019-01-05, the RH was in the order of $20-50 \%$ at the interior (warm) surface of the insulation layer (Fig. 10), 60-100\% at the exterior (cold) surface with perpendicular probe installation (Fig. 10 and 14) and $80-100 \%$ at the exterior surface with the parallel installation. It was expected that the measured RH would be close to $100 \%$ near the exterior surface during cold periods, but surprisingly RH decreased when the exterior temperature dropped and increased again when the exterior temperature became higher. On the other hand, the overall RH level was lowest near the warm surface and became higher towards the cold surface, which was in line with predictions.
The thermal bridge from the perpendicular probes decreased the RH, but because the overall behaviour was similar in parallel probes, the installation method does not seem to explain the low RH values during cold periods. The explanation could be, that the vapour pressure throughout the mineral wool insulation would have been near-constant and determined by the coldest point, whereas the temperature increased inwards from the exterior surface.

The rise in relative humidity during rising exterior temperature would be caused by the evaporated moisture being diffused to the measurement probe, which is still at a lower temperature. This would also require the sorption processes to happen quickly compared to other hygrothermal changes in the insulation layer.

\subsection{Radio monitoring results}

Figures 15 and 16 present measurement results from the radio wave measurements.

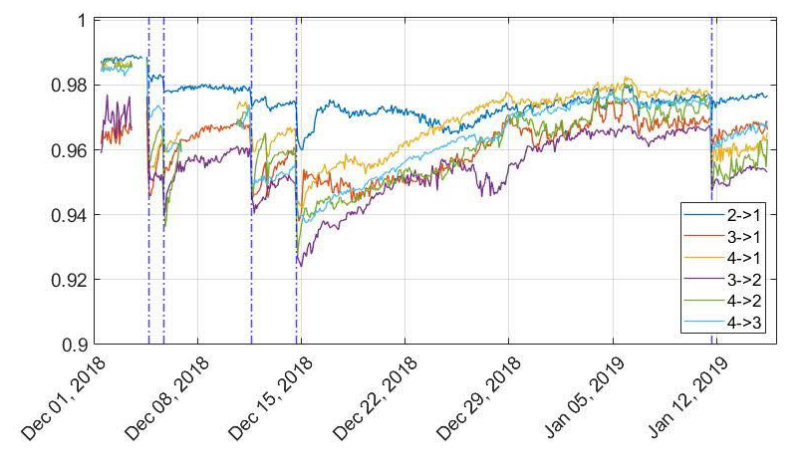

Fig. 15. Channel Impulse Response (CIR) values from radio measurements (1.12.-15.1.). The values drop each time water is injected into the insulation layer.

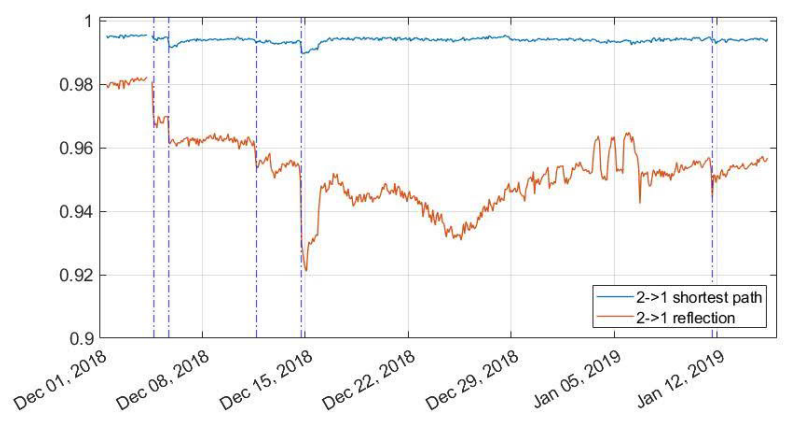

Fig. 16. Example of a received signal being divided (difference) into two parts and analysed separately. The upper blue line describes a short signal path from transmitter to receiver. The lower orange line is for a signal which has reflected multiple times from the test walls.

Fig. 15 shows a step-wise change in the channel impulse response (CIR) values when liquid water was added into the insulation layer. After the drop, the CIR values started to increase back to their previous levels.

Different post-processing methods can be used to separate interesting signals from the noise. Integration of the signals at Fig. 15 creates a smoother behaviour and while this can better highlight longer condensation periods during temperature variations, it can reduce the 
visibility of shorter step-wise changes from adding liquid water. The utilisation of reflected signals in Fig. 17 highlighted the condensation periods better compared Fig. 15 , but it also didn't maintain the water injection events as clearly.

The changes in temperature are not very visible in the radio monitoring data, for which one possible explanation is that the reflectivity and attenuation properties of steel and mineral wool are influenced by temperature changes only a little. Mechanical events to the building envelope such as truck bumps and loose flashings can change the signal behaviour and also be visible in the data.

\section{Conclusions}

This paper presented results on the laboratory measurements of mineral wool insulated sandwich panels. The temperature on the exterior side of the panels was adjusted while liquid water was injected into the insulation layer. The test structure was sealed from all sides during these tests.

The application of the GUM and/or Monte Carlo methods to determine the measurement uncertainty was considered useful and are recommended for future use.

The installation of $\mathrm{T} / \mathrm{RH}$ probes perpendicularly through the sandwich panels created a thermal bridge, which increased the temperature at the measurement point around $7-12 \%$ of the total temperature difference. Changes to vapour pressure were not as visible.

In constant-temperature conditions, the speed of evaporation from water leakage seemed to be the limiting factor for the increasing vapour pressure compared to the speed of vapour diffusion. The same spatially even vapour pressure was present also at the dynamic conditions after water injection. Due to this, detecting moisture leakage from a sandwich structure with a $\mathrm{T} / \mathrm{RH}$ measurement would be somewhat robust for the exact placing of the probe, but would require long measurement time (weeks) and be insensitive to large water leakages. From this perspective, water leakages to open-porous materials such as rain leakages should be modelled as maximum water content affecting a variable material volume, instead of the more common approach of fixing the material volume and adjusting the intensity of the moisture source.

In dynamic conditions relative humidity had its lowest values during decreasing exterior temperature and highest values when the exterior temperature rose again. This could be explained by a near-constant vapour pressure throughout the insulation layer, temperature increase inwards from the exterior surface, fast moisture adsorption and desorption processes and the evaporated moisture being diffused inwards when the exterior temperature rises again.

The radio wave monitoring showed a response especially to the injection of water, condensation periods and changes to the structure itself. These events can be considered to have changed the reflectivity of the steel sheets and the permeability of the material layers with regards to radio waves. Possible applications for the radio wave monitoring system could be the quick identification of structural or moisture-related fault events (due to fast response) or extra-long condition monitoring of steel sandwich panels (due to encapsulation and low price of radio electronics).

This work has received funding from the European Commission Research Fund for Coal and Steel, grant No. 754185; from Tampere University graduate school; from the Estonian Centre of Excellence in Zero Energy and Resource Efficient Smart Buildings and Districts, ZEBE (grant No. 2014-2020.4.01.150016) funded by the European Regional Development Fund, the Estonian Research Council (grant No. PRG483) and by European Commission through the H2020 project Finest Twins (grant No. 856602).

\section{References}

1. Davies, M. ed. (2001) Lightweight sandwich construction. Blackwell science, $370 \mathrm{p}$.

2. Barrett, P. et al., edited (2010) W056 - Special Track. $18^{\text {th }}$ CIB World Building Congress. May 2010 Salford, United Kingdom. CIB Publication 342.84 p.

3. Y.C. Wang, A. Foster, Fire Safety J. 90, 1-14 (2017)

4. Kalbe, K., Piikov, H., Kesti, J., Honkakoski, E., Kurnitski, J. \& Kalamees, T. Moisture dry-out from steel faced insulated sandwich panel in NSB 2020, Tallinn, Estonia.

5. Ruukki Construction Oy, Sandwich Panel SPA Energy external wall details. www.ruukki.com

6. Paroc CES 50 C. Structural wool/high density stone wool. Product specification. 22.5.2015

7. JCGM 100:2008 Evaluation of measurement data Guide to the expression of uncertainty in measurement. 27 p. +93 app. p. www.bipm.org

8. Rotronic technical note. Humidity Definitions. 3 p.

9. Rotronic. Main catalogue v16. Measurement devices for relative humidity, temperature, $\mathrm{CO} 2$ and differential pressure. $172 \mathrm{p}$. Accuracy of HC2 probes. N.B. Older sensors of the same model were used.

10. Rotronic Main Catalogue 2009/10. Humidity and temperature measurement. $102 \mathrm{p}$.

11. Humia Technologies Oy (2019) Humia B3 probes specifications. 1 p. www.humia.fi

12. Nicolai, A. (2008) Modeling and Numerical Simulation of Salt Transport and Phase Transitions in Unsaturated Porous Building Materials. Syracuse University.

13. LBNL (2019). THERM Two-Dimensional Building Heat-Transfer Modeling.

14. Saakian, A. (2011) Radio Wave Propagation Fundamentals. Artech house. 362 p.

15. ITU (2015) Recommendation ITU-R P.2040-1 (07/2015) Effects of building materials and structures on radiowave propagation above $100 \mathrm{MHz} .30 \mathrm{p}$.

16. Condition monitoring of building element or building structure. EP3051832B1, WO2016120445A1. Available at: https://patents.google.com/patent/EP3051832B1/en

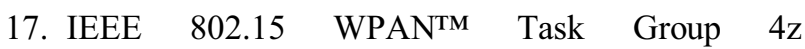
http://www.ieee802.org/15/pub/TG4z.html 